\title{
Long noncoding RNAs in Innate and Adaptive Immunity
}

\author{
Katherine A. Fitzgerald and Daniel R. Caffrey \\ Program in Innate Immunity, Division of Infectious Diseases and Immunology, Department of \\ Medicine, University of Massachusetts Medical School, Worcester, MA, USA
}

\begin{abstract}
The differentiation and activation of both innate and adaptive immune cells is highly dependent on a coordinated set of transcriptional and post-transcriptional events. Chromatin-modifiers and transcription factors regulate the accessibility and transcription of immune genes, respectively. Immune cells also express miRNA and RNA-binding proteins that provide an additional layer of regulation at the mRNA level. However, long noncoding RNA (lncRNA), which have been primarily studied in the context of genomic imprinting, cancer, and cell differentiation, are now emerging as important regulators of immune cell differentiation and activation. In this review, we provide a brief overview of IncRNA, their known functions in immunity, and discuss their potential to be more broadly involved in other aspects of the immune response.
\end{abstract}

\section{Introduction}

Cells of the immune system are equipped with the capacity to undergo dramatic changes in their transcriptional program in order to rapidly mobilize expression of genes important in host-defense. The differentiation and activation of both innate and adaptive immune cells is highly dependent on a coordinated set of transcriptional and post-transcriptional events. Hundreds of protein-coding genes are induced and repressed during both of these processes. For example, in the innate immune response, the bodies first line of defense against pathogen attack, dendritic cells and macrophages express both common and unique sets of toll-like receptors, intracellular signaling molecules, chemokines and cytokines [1]. Chromatin-modifying complexes determine which regions of the genome are accessible to transcription factors, which, in turn, help regulate transcription [2-4]. Furthermore, RNAbinding proteins and miRNA can regulate the products of transcription in various ways (e.g. protein translation, RNA turnover, and splicing). More recently, lncRNAs have been shown to regulate various biological process and several studies now suggest that they play important roles during the differentiation and activation of immune cells.

\section{Long noncoding RNAs}

lncRNAs are arbitrarily defined as noncoding RNAs that have at least 200 nucleotides and are described in several reviews [5-9]. Although the majority of a lncRNA sequence should lack coding potential, it is possible that some lncRNAs encode small peptides [10,11]. Therefore, it may be useful to define lncRNAs as long RNA molecules that perform molecular functions that are distinct from encoding proteins. In humans, lncRNAs are often

(c) 2013 Elsevier Ltd. All rights reserved.

Corresponding author: Caffrey, Daniel R (daniel.caffrey@umassmed.edu).

Publisher's Disclaimer: This is a PDF file of an unedited manuscript that has been accepted for publication. As a service to our customers we are providing this early version of the manuscript. The manuscript will undergo copyediting, typesetting, and review of the resulting proof before it is published in its final citable form. Please note that during the production process errors may be discovered which could affect the content, and all legal disclaimers that apply to the journal pertain. 
polyadenylated and their spliced transcripts can consist of one or more exons. In general, most lncRNAs have fewer exons than mRNA and are shorter than most mRNA[12].

Although several lncRNA were discovered and characterized prior to 2005 [13-15], advances in sequencing and array technologies have led to the discovery of thousands of lncRNA transcripts [16-18]. It is now known that at least $75 \%$ of the human genome is transcribed in one cell or another and the majority of these transcripts can be categorized as lncRNA [19]. Consequently, lncRNA genes are located in various chromosomal regions and can be regarded as the major class of RNA genes encoded by the genome. However, the functions of most lncRNA are unknown and it is therefore useful to classify lncRNA based on their location and proximity to protein-coding genes [5](Figure 1). Indeed, the names of many lncRNA are derived from their neighboring protein-coding genes. IncRNA that occur within the introns of protein-coding genes are aptly referred to as intronic lncRNA. Divergently transcribed lncRNA/mRNA pairs have 5' ends that are proximal to each other and are typically co-regulated [20]. We propose that lncRNA that do not overlap with a protein-coding gene are referred to as non-overlapping lncRNA. Although non-overlapping lncRNA are often referred to as intergenic lncRNA, the latter term is somewhat misleading as the majority of the genome contains bona fide genes that often happen to be lncRNA. When a lncRNA is complementary to another protein-coding or non-coding gene it can be classified as an antisense IncRNA or natural antisense transcript (NAT)[21]. A cis-NAT overlaps with its complementary gene, whereas a trans-NAT does not overlap with its complementary gene. The genesis of trans-NATs can probably be attributed to gene duplication events where the opposite strand has evolved the ability to be transcribed. Indeed, many lncRNAs are likely to be transcribed by so-called pseudogenes that no longer encode protein.

\section{Molecular functions of IncRNA}

The molecular functions of lncRNA are exceptionally diverse and several comprehensive reviews describe their mechanisms of action in detail [5-8,21]. The precise sequence and structure of a lncRNA probably determines the number and type of molecules (e.g. protein, mRNA, miRNA) that it interacts with. Through these interactions, lncRNA regulate a variety of processes that include transcription, splicing, RNA degradation, and translation (Figure 2).

Many lncRNA have been shown to interact with various chromatin-modifiers that alter the chemical structure of chromatin and determine the accessibility of DNA to transcription factors and RNA polymerases (e.g. Xist [22], Air [23], HOTAIR [24], Nest [25]). Other lncRNA are known to form ribonuceloproteins that regulate the transcription of specific sets of genes (e.g. lincRNA-Cox2 [26] and lincRNA-p21 [27]). lincRNA-p21 and hnRNP-K form a complex that bind specific regions of the genome and repress the transcription of genes in the p53 pathway. IncRNA can also act as decoys for DNA-binding proteins by mimicking the sequence or structure of the target DNA (e.g. gas5 [28], PANDA [29], DHFR minor [30] and possibly Lethe [31]). Like mRNA, IncRNA can also interact with miRNAs by hybridizing to partially complementary sequences [32,33] Additionally, some miRNAbinding lncRNA have the potential to act as molecular sponges that quench the effects of miRNA on their primary mRNA targets [34-39].

At least two lncRNA are known to regulate protein translation in one way or another. Several regions of lincRNA-p21 are complementary to the mRNA of CTNNB1 and JUNB, and binding of lincRNA-p21 to these mRNA is associated with their translational repression [40]. The antisense Uchl1 gene overlaps with two exons in the 5'-end of the Uchl1 proteincoding gene[41]. Antisense Uchl1 RNA promotes association of Uchl1 mRNA with active 
polysomes and enhances protein translation. A lncRNA that is antisense to the Zeb2 proteincoding gene affects Zeb2 protein-levels and may also regulate its translation [42]. Other lncRNAs are involved in different aspects of mRNA turnover, including mRNA decay and mRNA stabilization. Two lncRNAs, termed $1 / 2$-sbsRNAs are partially complementary to the 3'UTRs of some mRNA and have the potential to form a duplex. The IncRNA-mRNA duplexes are proposed to bind Staufen 1, which drives staufen-mediated mRNA decay [43]. BACE1-AS is a lncRNA that is anti-sense to the protein-coding gene that encodes $\beta$ secretase-1 (BACE1), an enzyme associated with Alzheimer's disease pathophysiology. BACE1-AS is proposed to protect BACE1 from mRNA degradation through base-paring of the respective transcripts [44]. IncRNA gadd7 interacts with TDP43, a protein that binds and stabilizes Cdk6 mRNA. The interaction between gadd7 and TDP43 leads to increased degradation of Cdk6 mRNA [45]. IncRNAs can also regulate alternative splicing of premRNAs. The lncRNA MALAT1 interacts with serine/arginine splicing factors, which affects the distribution of splicing factors in nuclear speckle domains and alternative splicing of pre-mRNA [46]. Small nucleolar lncRNAs (sno-lncRNAs) interact with FOX-family splicing factors and influence alternative splicing of pre-mRNAs [47].

\section{Expression of IncRNAs in immune cells}

To date, most lncRNA have been primarily studied in the context of genomic imprinting, cancer and cell differentiation [5,8]. However, IncRNA are now emerging as important regulators of various other biological processes, including the immune response. CD11c+ dendritic cells express lncRNAs when they are stimulated with lipopolysaccharide, an activator of TLR4 signaling [16]. CD8+ T cells express hundreds of lncRNA genes, many of which are specific to lymphocytes and are dynamically regulated during differentiation or activation [48]. CD4+ T cells are also reported to express many lncRNAs [49]. Hundreds of lncRNAs are expressed in mice exposed to severe acute respiratory virus or influenza virus [50], many of which are regulated downstream of type I IFN signaling. Rhabdomyosarcoma cells are also reported to express lncRNAs when they are infected with enterovirus 71 [51]. Although these studies clearly demonstrate that lncRNAs are expressed in different immunological contexts, their molecular functions are largely unexplored.

\section{IncRNAs in adaptive immunity}

In $\mathrm{T}_{\mathrm{h}} 2$ cells, lincR-Ccr2-5' AS is transcribed in the opposite direction of the chemokine Ccr2 and is located between Ccr3 ad Ccr3 [52]. Silencing of LincR-Ccr2-5' AS led to lower expression of the neighboring $\mathrm{Ccr} 1, \mathrm{Ccr} 2, \mathrm{Ccr} 3$, and $\mathrm{Ccr} 5$ genes. These chemokines are required for trafficking of $\mathrm{T}_{\mathrm{h}} 2$ cells to the lungs and knockdown of lincR-Ccr2-5' AS also reduced migration of $\mathrm{T}_{\mathrm{h}} 2$ cells to the lung.

TMEVPG1/ NeST is a lncRNA that was initially proposed to control Theiler's virus persistence in mice [53]. Following infection with Theiler's virus, TMEVPG1/ NeST is expressed in immune cells of susceptible SJL/J mice that develop persistent infection, but not in those from the resistant B10.S strain. TMEVPG1/ NeST is located in a region of the genome near the IFN- $\gamma$ gene. Earlier studies demonstrated that transcription of TMEVPG1/ NeST was $T_{h} 1$ selective and dependent on Stat 4 and T-bet, transcriptions factors that are involved in $\mathrm{T}_{\mathrm{h}} 1$ cell differentiation [54]. Gomez et al developed B10.S mice that express either the SJL/J-derived or B10.S-derived NeST RNA as a transgene in both CD4+ and CD8+ T cells [25]. Unlike the parental B10.S strain, which clear Theiler's virus, the B10.S mice that overexpress SJL/J-derived NeST, phenocopy the SJL/J parental strain by becoming persistently infected and developing demyelinating lesions in the brain. NeST also confers differential susceptibility to Salmonella enterica Typhimurium. B10.S mice succumb to lethal Salmonella infection, while SJL/J or the B10.S mice that overexpress the SJL/J- 
derived NeST were able to survive this infection. The higher expression of SJL/J derived $\mathrm{NeST}$ in these mice, led to the inducible synthesis of IFN $-\gamma$ in CD8+ T cells causing decreased Salmonella enterica pathogenesis. NeST acts as an enhancer-like lncRNA by enhancing transcription of IFN- $\gamma$. NeST RNA binds WDR5, which alters histone 3 lysine 4 trimethylation at the IFN- $\gamma$ locus. Consequently, both IFN- $\gamma$ RNA and IFN- $\gamma$ protein levels are increased in activated CD8+ T cells. Collectively, these findings highlight the importance of lncRNAs in host defense and indicate that like protein coding genes, lncRNAs can confer susceptibility to infectious diseases.

\section{IncRNAs in innate immunity}

Recently, several groups have provided increasing levels of evidence that collectively demonstrate the functional importance of IncRNAs in innate immunity [26,31,55,56]. A KIR antisense lncRNA is expressed in progenitor cells or pluripotent cell lines and its overexpression in NK cells leads to decreased expression of the KIR protein-coding gene [55]. KIR antisense lncRNA overlaps with KIR-coding exons 1 and 2, as well as a proximal promoter that is upstream of KIR. Transcription of KIR antisense lncRNA appears to be regulated by myeloid zinc finger 1, which leads to silencing of KIR through an unknown mechanism.

Tumor necrosis factor induces the expression of hundreds of lncRNAs in murine fibroblasts [31]. Among these, Lethe, a pseudogene lncRNA, is transcribed upon activation of $\mathrm{NFkB}$, a transcription factor important in inflammation. In turn, Lethe binds directly to RelA, a subunit of the NFKB heterodimeric transcription factor and inhibits NFKB DNA binding activity. These findings suggest that Lethe functions as a post-induction feedback regulator of TNF signaling in order to dampen the inflammatory response.

HOTAIRM1 is a lncRNA that is specifically expressed in myeloid cells [56]. It is antisense to the HOXA genes and is transcribed in NB4 promyelocytic leukemia cells that are activated by all-trans retinoic acid (ATRA) through the retinoic acid receptor. During ATRA-induced granulocyte maturation of NB4 cells, HOTAIRM1 is required for the expression of HOXA1, HOXA4, CD11b, and CD18. These results suggest that HOTAIRM plays an important role during granulocyte maturation.

A synthetic bacterial lipoprotein $\left(\mathrm{Pam}_{3} \mathrm{CSK}_{4}\right)$, that engages TLR2 induces the expression of 62 IncRNAs in mouse bone marrow-derived macrophages [26]. The most significantly induced lncRNAs tended to be located near protein-coding immune genes, suggesting coregulation of these neighboring genes. lincRNA-Cox 2 was amongst the most highly induced of these lncRNAs and is proximal to the prostaglandin-endoperoxide synthase 2 (Ptgs2/ Cox2) gene. TLR ligands as well as other inflammatory triggers induced co-expression of both lincRNA-Cox 2 and its neighboring Ptgs2 (Cox2) gene. lincRNA-Cox2 was shown to both positively and negatively regulate the transcription of distinct classes of immune genes. In the unstimulated state, lincRNA-Cox 2 repressed the expression of 787 genes, including chemokines ( $\mathrm{Ccl} 5, \mathrm{Cx} 3 \mathrm{cl} 1)$, chemokine receptors $(\mathrm{Ccrl})$ and interferon-stimulated genes (ISGs) (Irf7, Oas1a, Oas11, Oas2, Ifi204 and Isg15). However, stimulation of TLR2 with Pam3CSK4, induced the expression of 713 distinct genes that were dependent on lincRNACox2, including Tlr1, Il6 and Il23a. Transcriptional repression of the target genes (e.g. Cc15) was primarily mediated by interactions of lincRNA-Cox 2 with heterogeneous nuclear ribonucleoprotein $\mathrm{A} / \mathrm{B}$ and $\mathrm{A} 2 / \mathrm{B} 1$. However, these two hnRNP proteins were not involved in coordinating the TLR induced transcription of IL6, suggesting that lincRNA-Cox 2 forms additional regulatory complexes. 


\section{IncRNAs and modulation of host-pathogen interactions}

It is likely that some lncRNAs participate in host-pathogen interactions that alter the resulting immune response. Many viruses encode miRNA that target host mRNA and are important for viral replication and immune evasion [57]. It is therefore conceivable that host cells express lncRNA that quench the effects of these viral miRNA during an immune response. While some lncRNAs (e.g. lincRNA-Cox2) repress anti-viral gene expression, it is also conceivable that viruses or other pathogens utilize these host lncRNAs to thwart induction of anti-viral genes.

IncRNAs have been described in plasmodium falciparum and several viruses [58-60]. The viral lncRNA are often smaller than 200 nucleotides and regulate a variety of processes, including viral latency, apoptosis, and immunity. Kaposi's sarcoma-associated herpesvirus (KSHV) expresses a polyadenylated nuclear RNA (lncRNA-PAN) that interacts with IRF4 and is proposed to inhibit transcription of IL-4, IL-18, and IFN $\gamma$ [61]. In T cells, Herpesvirus expresses the non-coding RNAs HSUR1 and HSUR2, which interact with the host miRNA miR-27. This interaction leads to degradation of the miRNA and altered expression of its target genes[62].

\section{Conclusions}

To date, more than a hundred human IncRNAs with experimentally determined biological functions have been annotated in lncrna db [63]. We propose that lncRNA have the potential to perform a variety of molecular functions in the immune system (Figure 2). However, there are multiple challenges and concerns associated with the functional characterization of lncRNAs [9]. It is possible that some lncRNA are the product of promiscuous transcription or only perform minor molecular functions [64]. Many human lncRNA do not have obvious homologs in mouse [12], and it will be important to determine whether species-specific IncRNA are responsible for major differences between the mouse and human immune systems. It is paramount that the functions of lncRNA in immunity are carefully assessed in genetically manipulated mice. Just like protein-coding genes, genetic manipulation of some IncRNA will produce a dramatic phenotype [25,65], while others will lack an obvious phenotype [66,67]. Many lncRNA appear to be expressed at low levels in immune cells [26] and it will be important to determine their functional relevance. While it is tempting to dismiss lncRNA with low expression values as transcriptional noise, it is likely that current methods to detect transcription are not sufficiently sensitive. Furthermore, it should be noted that relatively low levels of NeST ( 0.5 molecules/cell) produce a dramatic phenotype [25]. As many lncRNA are specifically expressed in certain cell types or subcellular compartments [68], it will also be important to assess the expression of lncRNA in different immune cells and their respective compartments. In summary, we propose that IncRNA will be involved various aspects of the immune response that will often be specific to a particular immune cell or subcellular location. A better understanding of the biology of these genes could uncover new targets for therapeutic intervention in both infectious and inflammatory diseases.

\section{References and recommended reading}

Papers of particular interest, published within the period of review, have been highlighted as:

- of special interest

•• of outstanding interest 
1. Chaussabel D. Unique gene expression profiles of human macrophages and dendritic cells to phylogenetically distinct parasites. Blood. 2003; 102:672-681. [PubMed: 12663451]

2. Nusinzon I. Interferon-stimulated transcription and innate antiviral immunity require deacetylase activity and histone deacetylase 1. Proceedings of the National Academy of Sciences. 2003; 100:14742-14747.

3. Foster SL, Hargreaves DC, Medzhitov R. Gene-specific control of inflammation by TLR-induced chromatin modifications. Nature. 2007; 447:972-978. [PubMed: 17538624]

4. Doyle SL, O'Neill LAJ. Toll-like receptors: From the discovery of NFkB to new insights into transcriptional regulations in innate immunity. Biochemical Pharmacology. 2006; 72:1102-1113. [PubMed: 16930560]

5. Rinn JL, Chang HY. Genome Regulation by Long Noncoding RNAs. Annu. Rev. Biochem. 2012; 81:145-166. [PubMed: 22663078] •• A comprehensive review of lncRNA

6. Guttman M, Rinn JL. Modular regulatory principles of large non-coding RNAs. Nature. 2012; 482:339-346. [PubMed: 22337053]

7. Yoon J-H, Abdelmohsen K, Gorospe M. Post-transcriptional gene regulation by long noncoding RNA. J. Mol. Biol. 2012

8. Hu W, Alvarez-Dominguez JR, Lodish HF. Regulation of mammalian cell differentiation by long non-coding RNAs. EMBO Rep. 2012; 13:971-983. [PubMed: 23070366] •• A carefully considered review of lncRNAs in mammalian cell differentiation

9. Ulitsky I, Bartel DP. lincRNAs: Genomics, Evolution, and Mechanisms. Cell. 2013; 154:26-46. [PubMed: 23827673]

10. Guttman M, Russell P, Ingolia NT, Weissman JS, Lander ES. Ribosome Profiling Provides Evidence that Large Noncoding RNAs Do Not Encode Proteins. Cell. 2013

11. Ingolia NT, Lareau LF, Weissman JS. Ribosome profiling of mouse embryonic stem cells reveals the complexity and dynamics of mammalian proteomes. Cell. 2011; 147:789-802. [PubMed: 22056041]

12. Derrien T, Johnson R, Bussotti G, Tanzer A, Djebali S, Tilgner H, Guernec G, Martin D, Merkel A, Knowles DG, et al. The GENCODE v7 catalog of human long noncoding RNAs: Analysis of their gene structure, evolution, and expression. Genome Research. 2012; 22:1775-1789. [PubMed: 22955988]

13. Pachnis V, Brannan CI, Tilghman SM. The structure and expression of a novel gene activated in early mouse embryogenesis. The EMBO Journal. 1988; 7:673-681. [PubMed: 3396539]

14. Brannan CI, Dees EC, Ingram RS, Tilghman SM. The product of the H19 gene may function as an RNA. Molecular and Cellular Biology. 1990; 10:28-36. [PubMed: 1688465]

15. Penny GD, Kay GF, Sheardown SA, Rastan S, Brockdorff N. Requirement for Xist in X chromosome inactivation. Nature. 1996; 379:131-137. [PubMed: 8538762]

16. Guttman M, Amit I, Garber M, French C, Lin MF, Feldser D, Huarte M, Zuk O, Carey BW, Cassady JP, et al. Chromatin signature reveals over a thousand highly conserved large non-coding RNAs in mammals. Nature. 2009; 458:223-227. [PubMed: 19182780]

17. Kapranov P, Cawley SE, Drenkow J, Bekiranov S, Strausberg RL, Fodor SPA, Gingeras TR. Large-scale transcriptional activity in chromosomes 21 and 22. Science. 2002; 296:916-919. [PubMed: 11988577]

18. Mercer TR, Dinger ME, Mattick JS. Long non-coding RNAs: insights into functions. Nat Rev Genet. 2009; 10:155-159. [PubMed: 19188922]

19. Djebali S, Davis CA, Merkel A, Dobin A, Lassmann T, Mortazavi A, Tanzer A, Lagarde J, Lin W, Schlesinger F, et al. Landscape of transcription in human cells. Nature. 2012; 489:101-108. [PubMed: 22955620]

20. Sigova AA, Mullen AC, Molinie B, Gupta S, Orlando DA, Guenther MG, Almada AE, Lin C, Sharp PA, Giallourakis CC, et al. Divergent transcription of long noncoding RNA/mRNA gene pairs in embryonic stem cells. Proceedings of the National Academy of Sciences. 2013; 110:28762881.

21. Magistri M, Faghihi MA, Laurent GS III, Wahlestedt C. Regulation of chromatin structure by long noncoding RNAs: focus on natural antisense transcripts. Trends in Genetics. 2012 
22. Zhao J, Sun BK, Erwin JA, Song JJ, Lee JT. Polycomb Proteins Targeted by a Short Repeat RNA to the Mouse X Chromosome. Science. 2008; 322:750-756. [PubMed: 18974356]

23. Nagano T, Mitchell JA, Sanz LA, Pauler FM, Ferguson-Smith AC, Feil R, Fraser P. The Air noncoding RNA epigenetically silences transcription by targeting G9a to chromatin. Science. 2008; 322:1717-1720. [PubMed: 18988810]

24. Tsai MC, Manor O, Wan Y, Mosammaparast N, Wang JK, Lan F, Shi Y, Segal E, Chang HY. Long Noncoding RNA as Modular Scaffold of Histone Modification Complexes. Science. 2010; 329:689-693. [PubMed: 20616235]

25. Gomez JA, Wapinski OL, Yang YW, Bureau J-F, Gopinath S, Monack DM, Chang HY, Brahic M, Kirkegaard K. The NeST Long ncRNA Controls Microbial Susceptibility and Epigenetic Activation of the Interferon- $\gamma$ Locus. Cell. 2013; 152:743-754. [PubMed: 23415224] • Using mouse genetics, this study demonstrates that a lncRNA (NeST) can dramatically alter the susceptibility and adaptive immune response of a mouse to two different pathogens. Furthermore, a relatively small number of lncRNA molecules are responsible for these altered phenotypes.

26. Carpenter S, Aiello D, Atianand MK, Ricci EP, Gandhi P, Hall LL, Byron M, Monks B, HenryBezy M, Lawrence JB, et al. A Long Noncoding RNA Mediates Both Activation and Repression of Immune Response Genes. Science. 2013; 341:789-792. [PubMed: 23907535] •• This study demonstrates that hundreds of immune genes are both positively and negatively regulated by lincRNA-Cox 2 during an innate immune response. Many of the target genes are repressed at the transcriptional level and are mediated by a RNP complex that consists of lincRNA-Cox 2 and hnRNP A/B or hnRNP A2/B1.

27. Huarte M, Guttman M, Feldser D, Garber M, Koziol MJ, Kenzelmann-Broz D, Khalil AM, Zuk O, Amit I, Rabani M, et al. A Large Intergenic Noncoding RNA Induced by p53 Mediates Global Gene Repression in the p53 Response. Cell. 2010; 142:409-419. [PubMed: 20673990]

28. Kino T, Hurt DE, Ichijo T, Nader N, Chrousos GP. Noncoding RNA gas5 is a growth arrest- and starvation-associated repressor of the glucocorticoid receptor. Science Signaling. 2010; 3:ra8. [PubMed: 20124551]

29. Hung T, Wang Y, Lin MF, Koegel AK, Kotake Y, Grant GD, Horlings HM, Shah N, Umbricht C, Wang P, et al. Extensive and coordinated transcription of noncoding RNAs within cell-cycle promoters. Nat Genet. 2011; 43:621-629. [PubMed: 21642992]

30. Martianov I, Ramadass A, Serra Barros A, Chow N, Akoulitchev A. Repression of the human dihydrofolate reductase gene by a non-coding interfering transcript. Nature. 2007; 445:666-670. [PubMed: 17237763]

31. Rapicavoli NA, Qu K, Zhang J, Mikhail M, Laberge R-M, Chang HY, Gingeras T. A mammalian pseudogene lncRNA at the interface of inflammation and anti-inflammatory therapeutics. eLife. 2013; 2 - This study demonstrates that a lncRNA can modulate a transcription factor that is essential to the immune response.

32. Licatalosi DD, Mele A, Fak JJ, Ule J, Kayikci M, Chi SW, Clark TA, Schweitzer AC, Blume JE, Wang X, et al. HITS-CLIP yields genome-wide insights into brain alternative RNA processing. Nature. 2008; 456:464-469. [PubMed: 18978773]

33. Zhang Z, Zhu Z, Watabe K, Zhang X, Bai C, Xu M, Wu F, Mo YY. Negative regulation of lncRNA GAS5 by miR-21. Cell Death Differ. 2013

34. Cesana M, Cacchiarelli D, Legnini I, Santini T, Sthandier O, Chinappi M, Tramontano A, Bozzoni I. A Long Noncoding RNA Controls Muscle Differentiation by Functioning as a Competing Endogenous RNA. Cell. 2011; 147:358-369. [PubMed: 22000014]

35. Sumazin P, Yang X, Chiu H-S, Chung W-J, Iyer A, Llobet-Navas D, Rajbhandari P, Bansal M, Guarnieri P, Silva J, et al. An Extensive MicroRNA-Mediated Network of RNA-RNA Interactions Regulates Established Oncogenic Pathways in Glioblastoma. Cell. 2011; 147:370-381. [PubMed: 22000015]

36. Rubio-Somoza I, Weigel D, Franco-Zorilla J-M, García JA, Paz-Ares J. ceRNAs: miRNA target mimic mimics. Cell. 2011; 147:1431-1432. [PubMed: 22196719]

37. Karreth FA, Tay Y, Perna D, Ala U, Tan SM, Rust AG, DeNicola G, Webster KA, Weiss D, Perez-Mancera PA, et al. In vivo identification of tumor-suppressive PTEN ceRNAs in an oncogenic BRAF-induced mouse model of melanoma. Cell. 2011; 147:382-395. [PubMed: 22000016] 
38. Tay Y, Kats L, Salmena L, Weiss D, Tan SM, Ala U, Karreth F, Poliseno L, Provero P, Di Cunto F, et al. Coding-Independent Regulation of the Tumor Suppressor PTEN by Competing Endogenous mRNAs. Cell. 2011; 147:344-357. [PubMed: 22000013]

39. Faghihi MA, Zhang M, Huang J, Modarresi F, Van der Brug MP, Nalls MA, Cookson MR, StLaurent G, Wahlestedt C. Evidence for natural antisense transcript-mediated inhibition of microRNA function. Genome Biology. 2010; 11:R56. [PubMed: 20507594]

40. Yoon J-H, Abdelmohsen K, Srikantan S, Yang X, Martindale JL, De S, Huarte M, Zhan M, Becker KG, Gorospe M. LincRNA-p21 Suppresses Target mRNA Translation. Molecular Cell. 2012; 47:648-655. [PubMed: 22841487]

41. Carrieri C, Cimatti L, Biagioli M, Beugnet A, Zucchelli S, Fedele S, Pesce E, Ferrer I, Collavin L, Santoro C, et al. Long non-coding antisense RNA controls Uchl1 translation through an embedded SINEB2 repeat. Nature. 2012

42. Beltran M, Puig I, Pena C, Garcia JM, Alvarez AB, Pena R, Bonilla F, de Herreros AG. A natural antisense transcript regulates Zeb2/Sip1 gene expression during Snail1-induced epithelialmesenchymal transition. Genes \& Development. 2008; 22:756-769. [PubMed: 18347095]

43. Gong C, Maquat LE. lncRNAs transactivate STAU1-mediated mRNA decay by duplexing with $3^{\prime}$ UTRs via Alu elements. Nature. 2011; 470:284-288. [PubMed: 21307942]

44. Faghihi MA, Modarresi F, Khalil AM, Wood DE, Sahagan BG, Morgan TE, Finch CE, St-Laurent G, Kenny PJ, Wahlestedt C. Expression of a noncoding RNA is elevated in Alzheimer's disease and drives rapid feed-forward regulation of beta-secretase. Nat. Med. 2008; 14:723-730. [PubMed: 18587408]

45. Liu X, Li D, Zhang W, Guo M, Zhan Q. Long non-coding RNA gadd7 interacts with TDP-43 and regulates Cdk6 mRNA decay [Internet]. The EMBO Journal. 2012

46. Tripathi V, Ellis JD, Shen Z, Song DY, Pan Q, Watt AT, Freier SM, Bennett CF, Sharma A, Bubulya PA, et al. The Nuclear-Retained Noncoding RNA MALAT1 Regulates Alternative Splicing by Modulating SR Splicing Factor Phosphorylation. Molecular Cell. 2010; 39:925-938. [PubMed: 20797886]

47. Yin Q-F, Yang L, Zhang Y, Xiang J-F, Wu Y-W, Carmichael GG, Chen LL. Long Noncoding RNAs with snoRNA Ends. Molecular Cell. 2012; 48:219-230. [PubMed: 22959273]

48. Pang KC, Dinger ME, Mercer TR, Malquori L, Grimmond SM, Chen W, Mattick JS. Genomewide identification of long noncoding RNAs in CD8+ T cells. The Journal of Immunology. 2009; 182:7738-7748. [PubMed: 19494298] • This study suggests that lymphoid cells express specific repertoires of lncRNA that are likely to regulate T-cell differentiation and activation.

49. Pagani M, Rossetti G, Panzeri I, de Candia P, Bonnal RJP, Rossi RL, Geginat J, Abrignani S. Role of microRNAs and long-non-coding RNAs in CD4 +T-cell differentiation. Immunol Rev. 2013; 253:82-96. [PubMed: 23550640]

50. Peng X, Gralinski L, Armour CD, Ferris MT, Thomas MJ, Proll S, Bradel-Tretheway BG, Korth MJ, Castle JC, Biery MC, et al. Unique Signatures of Long Noncoding RNA Expression in Response to Virus Infection and Altered Innate Immune Signaling. mBio. 2010; 1:e00206-10e00206-18. [PubMed: 20978541]

51. Yin Z, Guan D, Fan Q, Su J, Zheng W, Ma W, Ke C. IncRNA expression signatures in response to enterovirus 71 infection. Biochemical and Biophysical Research Communications. 2013; 430:629633. [PubMed: 23220233]

52. Hu G, Tang Q, Sharma S, Yu F, Escobar TM, Muljo SA, Zhu J, Zhao K. Expression and regulation of intergenic long noncoding RNAs during T cell development and differentiation. Nat Immunol. 2013

53. Vigneau S, Rohrlich P-S, Brahic M, Bureau J-F. Tmevpg1, a candidate gene for the control of Theiler's virus persistence, could be implicated in the regulation of gamma interferon. Journal of Virology. 2003; 77:5632-5638. [PubMed: 12719555]

54. Collier SP, Collins PL, Williams CL, Boothby MR, Aune TM. Cutting Edge: Influence of Tmevpg1, a Long Intergenic Noncoding RNA, on the Expression of Ifng by Th1 Cells. The Journal of Immunology. 2012; 189:2084-2088. [PubMed: 22851706] 
55. Wright PW, Huehn A, Cichocki F, Li H, Sharma N, Dang H, Lenvik TR, Woll P, Kaufman D, Miller JS, et al. Identification of a KIR antisense lncRNA expressed by progenitor cells. Genes Immun. 2013

56. Zhang X, Lian Z, Padden C, Gerstein MB, Rozowsky J, Snyder M, Gingeras TR, Kapranov P, Weissman SM, Newburger PE. A myelopoiesis-associated regulatory intergenic noncoding RNA transcript within the human HOXA cluster. Blood. 2009; 113:2526-2534. [PubMed: 19144990] • This study demonstrates that lncRNA play an important role during granulocyte maturation and suggest that lncRNAs are probably important in the differentiation of other immune cells.

57. Skalsky RL, Cullen BR. Viruses, microRNAs, and Host Interactions. Annu. Rev. Microbiol. 2010; 64:123-141. [PubMed: 20477536]

58. Broadbent KM, Park D, Wolf AR, Van Tyne D, Sims JS, Ribacke U, Volkman S, Duraisingh M, Wirth D, Sabeti PC, et al. A global transcriptional analysis of Plasmodium falciparum malaria reveals a novel family of telomere-associated lncRNAs. Genome Biology. 2011; 12:R56. [PubMed: 21689454]

59. Scaria V, Pasha A. Long Non-Coding RNAs in Infection Biology. Front. Gene. 2012; 3:308.

60. Zhang Q, Jeang K-T. Long noncoding RNAs and viral infections. BioMedicine. 2013; 3:34-42.

61. Rossetto CC, Pari GS. Kaposi's sarcoma-associated herpesvirus noncoding polyadenylated nuclear RNA interacts with virus- and host cell-encoded proteins and suppresses expression of genes involved in immune modulation. Journal of Virology. 2011; 85:13290-13297. [PubMed: 21957289]

62. Cazalla D, Yario T, Steitz JA. Down-Regulation of a Host MicroRNA by a Herpesvirus saimiri Noncoding RNA. Science. 2010; 328:1563-1566. [PubMed: 20558719]

63. Amaral PP, Clark MB, Gascoigne DK, Dinger ME, Mattick JS. lncRNAdb: a reference database for long noncoding RNAs. Nucleic Acids Research. 2011; 39:D146-D151. [PubMed: 21112873]

64. Bird A. Genome Biology: Not Drowning but Waving. Cell. 2013; 154:951-952. [PubMed: 23993086]

65. Ulitsky I, Shkumatava A, Jan CH, Sive H, Bartel DP. Conserved Function of lincRNAs in Vertebrate Embryonic Development despite Rapid Sequence Evolution. Cell. 2011; 147:15371550. [PubMed: 22196729]

66. Zhang B, Arun G, Mao YS, Lazar Z, Hung G, Bhattacharjee G, Xiao X, Booth CJ, Wu J, Zhang C, et al. The lncRNA Malat1 is dispensable for mouse development but its transcription plays a cisregulatory role in the adult. Cell Rep. 2012; 2:111-123. [PubMed: 22840402]

67. Nakagawa S, Ip JY, Shioi G, Tripathi V, Zong X, Hirose T, Prasanth KV. Malat1 is not an essential component of nuclear speckles in mice. [no date], [no volume].

68. Mercer TR, Dinger ME, Sunkin SM, Mehler MF, Mattick JS. Specific expression of long noncoding RNAs in the mouse brain. Proceedings of the National Academy of Sciences. 2008; 105:716-721. 


\section{Highlights}

IncRNAs are the largest class of non-coding RNA genes in mammalian genomes.

IncRNAs are expressed in a variety of immune cells.

Recent studies demonstrate that IncRNA perform major functions in innate and immune cells. 


\section{Intronic}

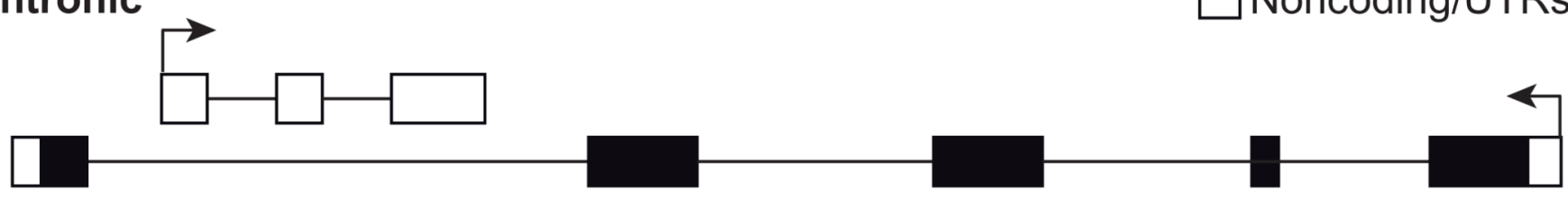

\section{Divergent}

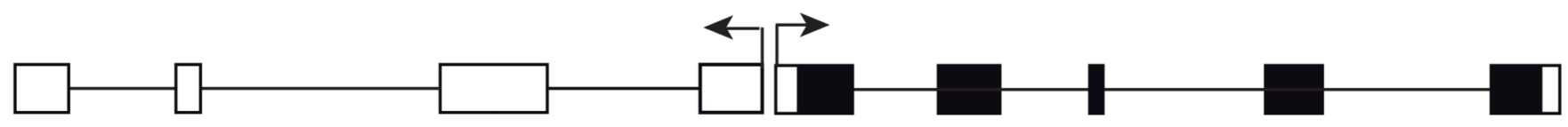

\section{Non-overlapping}

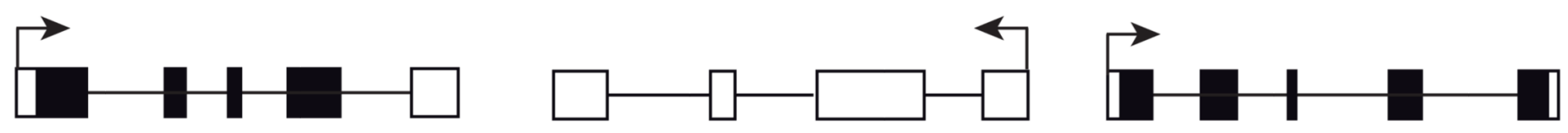

\section{Antisense}
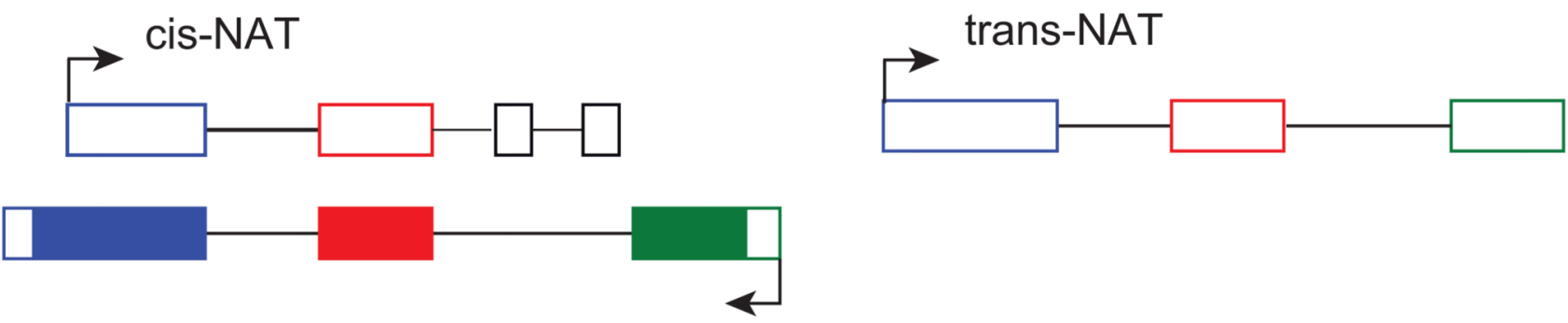

Figure 1.

Classification of lncRNA relative to protein-coding genes. Arrows indicate the direction of transcription. IncRNA contain non-coding exons (unfilled boxes). mRNA exons are composed of coding regions (filled boxes) and UTRs (unfilled boxes). Intronic lncRNA are located within an intron of a protein-coding gene in either direction and do not overlap with exons in the protein-coding gene. Divergent lncRNA/mRNA pairs are have proximal 5'ends and are transcribed in opposite directions. Non-overlapping lncRNA do not overlap with protein-coding genes and are also referred to as intergenic or interleaved lncRNA. cisNATS are natural antisense transcripts that are complementary to an overlapping transcript. Here, the individual exons of the protein-coding gene have unique colors (blue, red, and green) and the colors of the cisNAT indicate corresponding regions of complementarity. transNATs are complementary to a non-overlapping transcript in a different genomic location (inter- or intra-chromosomal) where the colors indicate regions of complementarity. Adapted from Rinn and Chang [5] 


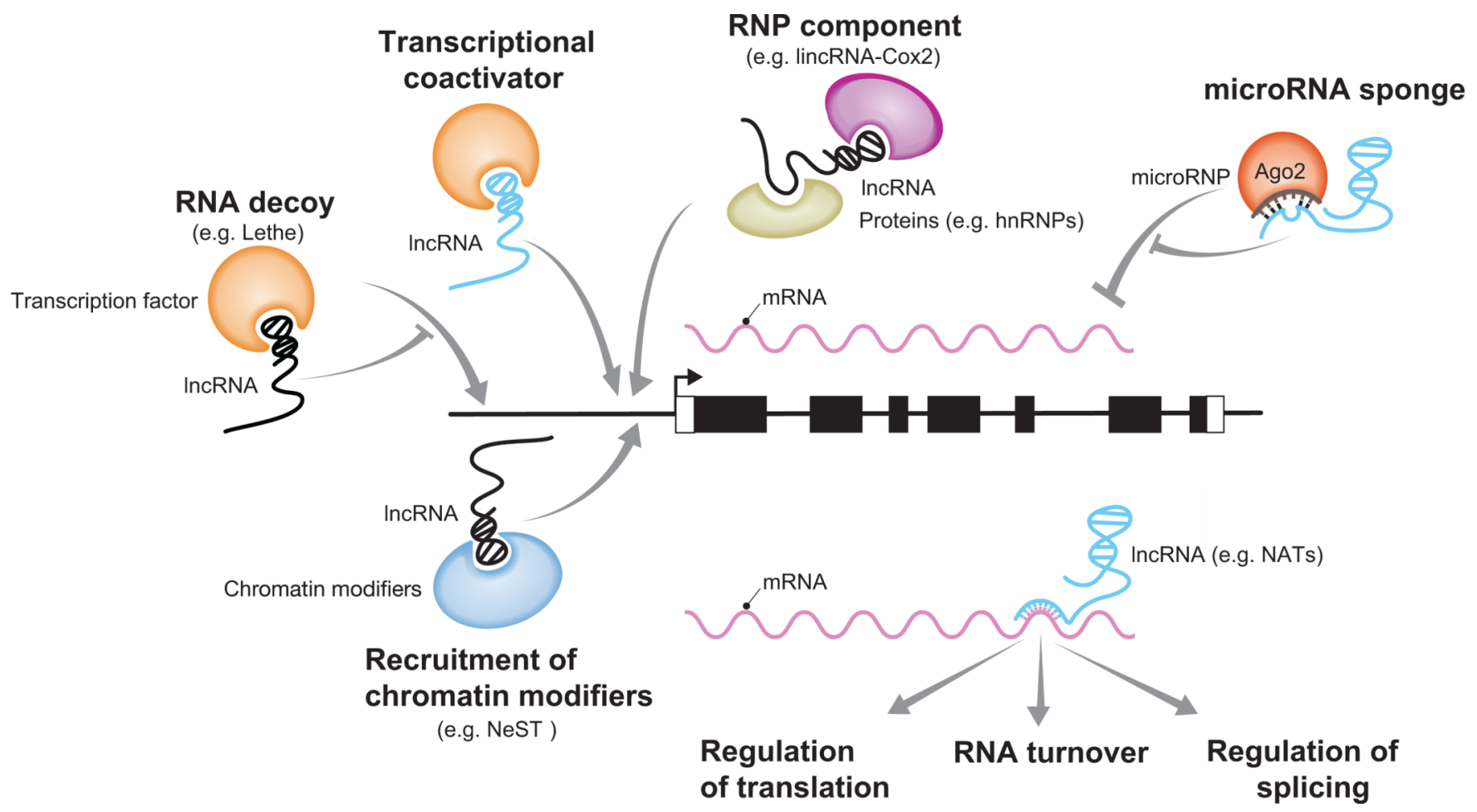

Figure 2.

Known and proposed functions of lncRNA in immunity. IncRNAs typically regulate transcription of a gene by forming complexes that bind a genomic region upstream of the transcription start site. IncRNA can potentially interact with other transcripts and regulate miRNA pathways, translation, splicing, and RNA turnover. IncRNAs with known molecular functions in immunity are colored black. Potential molecular functions for lncRNA in immunity are colored blue. Adapted from Hu et al [8]. lncRNA: long non-coding RNA, mRNA: messenger RNA, RNP: Ribonucleoprotein, hnRNPs: Heterogenous Ribonucleoproteins, NATs: Natural antisense transcripts. 